NBER WORKING PAPER SERIES

\title{
THE ECONOMICS OF CARBON OFFSETS
}

\author{
James B. Bushnell \\ Working Paper 16305 \\ http://www.nber.org/papers/w16305
NATIONAL BUREAU OF ECONOMIC RESEARCH
1050 Massachusetts Avenue
Cambridge, MA 02138
August 2010

I am grateful for helpful discussion and comments from Severin Borenstein, Tristan Brown, Kala Krishna, Erin Mansur, and Stephen Holland. The views expressed herein are those of the author and do not necessarily reflect the views of the National Bureau of Economic Research.

NBER working papers are circulated for discussion and comment purposes. They have not been peerreviewed or been subject to the review by the NBER Board of Directors that accompanies official NBER publications.

(C) 2010 by James B. Bushnell. All rights reserved. Short sections of text, not to exceed two paragraphs, may be quoted without explicit permission provided that full credit, including $\bigcirc$ notice, is given to the source. 
The Economics of Carbon Offsets

James B. Bushnell

NBER Working Paper No. 16305

August 2010

JEL No. H23,L14,L5,Q54

\section{$\underline{\text { ABSTRACT }}$}

Although international programs for carbon offsets play an important role in current and prospective climate-change policy, they continue to be very controversial. Asymmetric information creates several incentive problems, include adverse selection and moral hazard, in offset markets. The current regulatory focus on additionality tends to paint all these problems with a broad brush without proper consideration of the context or their implications.

James B. Bushnell

Department of Economics

468H Heady Hall

Iowa State University

Ames, IA 50011

and NBER

jimb@iastate.edu 


\title{
The Economics of Carbon Offsets
}

\author{
James B. Bushnell*
}

June, 2010

\begin{abstract}
Although international programs for carbon offsets play an important role in current and prospective climate-change policy, they continue to be very controversial. Asymmetric information creates several incentive problems, include adverse selection and moral hazard, in offset markets. The current regulatory focus on additionality tends to paint all these problems with a broad brush without proper consideration of the context or their implications.
\end{abstract}

\section{The Motivation for Offset Markets}

The evolution and growth of offset markets is recounted in Lecoq and Ambrosi (2007), and Grubb, et al. (2010). The most significant current global offset program, the Clean Development Mechanism, emerged from the Kyoto treaty. It combined the desires for flexible market-based mechanisms with the goal of financing a low-carbon development trajectory in emerging economies. Offset mechanisms comprise a prominent part of the proposed U.S. $\mathrm{CO}_{2}$ market articulated in H.R. 2454 (the "Waxman-Markey" bill). There are also important roles for offsets in regional U.S. carbon markets such as in California and the northeast U.S. as well as for voluntary carbon offset markets.

The primary distinction between offset programs and other forms of regulation are that offsets pay firms to reduce their emissions rather than raise the costs of continuing to emit. The entire concept of offset programs is therefore closely related to the question

*Associate Professor, Cargill Chair in Energy Economics, Dept. of Economics, Iowa State University, and NBER. Email: jimb@iastate.edu. I am grateful for helpful discussion and comments from Severin Borenstein, Tristan Brown, Kala Krishna, Erin Mansur, and Stephen Holland. 
of the 'reach' of traditional regulations. If all sources of emissions would fall under traditional regulations, there would be no need to extend those regulations through offsets. There are many reasons why traditional regulatory measures may be constrained. In the case of greenhouse gas (GHG) emissions, the most obvious is that emissions from any given jurisdiction hold consequences for the entire world. The fact that environmental damages span boundaries far greater than the reach of even international organizations makes the consistent application of traditional regulation almost impossible. A second reason is practicality. The effective implementation of cap-and-trade mechanisms requires reasonable monitoring and transactions costs for the sources falling under the cap. Some non-point sources of GHG emissions, such as those associated with land-use, would be difficult to integrate into a cap-and-trade program under any circumstances. A third reason is political; some sectors may simply be more successful at convincing governments that they should be exempted from mandatory emissions limits.

If we accept the fact that some countries and economic sectors are unlikely to fall under a mandatory limit on their GHG emissions, the question then becomes how best to motivate those sectors to reduce emissions. Ideally those actions would be coordinated in some fashion with the sectors that are directly regulated. This is where offset markets come into play.

Although the fundamental need for offsets is rooted in the limits of regulatory jurisdiction, today's programs are in fact motivated by a host of goals. A primary goal for many regulated industries is cost control. The prospect of a deep pool of offset projects providing a potentially low-cost supply of reductions creates an effective cap on allowance prices in a cap-and-trade system. ${ }^{1}$ Among developing nations and many NGO's, offset mechanisms have been seen as an important new source of capital to aid in development and the alleviation of poverty. For firms and individuals outside of sectors that might fall directly under a cap, such as the U.S. agricultural sector, an offset mechanism offers a potentially lucrative new source of revenue. ${ }^{2}$

From the perspective of economic efficiency, the great promise of an offset market is the potential for reducing GHG emissions at a much lower cost. To the extent that lowcost options for reducing emissions exist in sectors that are not directly regulated under

\footnotetext{
${ }^{1}$ The economic analysis of proposed GHG regulations by agencies such as U.S. Environmental Protection Agency and the California Air Resources Board highlight the sensitivity of future allowance prices to the cost and availability of offsets.

${ }^{2}$ USDA, 2009.
} 
a cap, an offset market allows for these "low-hanging fruit" to be harvested in place of more expensive reductions from the capped sector. For example, if the marginal source of abatement under the european emission trading system (ETS) costs 20 euro/ton, and the opportunity cost of preventing a similar ton of CO2e through deforestation in Africa is 2 euro/ton, the same level of CO2e emissions could be achieved at a cost 18 less euros if a european firm were allowed to offset its ETS emissions by financing the African project.

This relates closely to the notion of extending the jurisdiction of a cap. If there were no jurisdictional or measurement issues, these same efficiencies could be reaped by simply placing all relevant sectors under the same cap-and-trade regime. As I discuss below, this "maximum cap" approach would also avoid many of the information and incentive problems that are of such concern in offset markets. However, the reality given both domestic and international political and legal constraints is that important sectors and countries will be outside of a binding cap-and-trade regime. The question is therefore whether the informational and incentive problems with offset markets can be sufficiently overcome to capture these potential savings.

\section{Criticisms of Offset Markets}

Despite the alluring potential of offset mechanisms for reducing mitigation costs and overcoming jurisdictional boundaries, the programs remain quite controversial. At the heart of most criticisms of offset programs is the concern that the programs are not in fact yielding the emissions reductions implied by their transacted quantities. In this section I discuss the various types of enforcement concerns in the context of the more general economic and regulatory issues to which they are related. In the following section I explore the various methodologies that have been applied to mitigating these problems.

One can attribute most potential verification and enforcement problems to three key institutional factors that dominate offset programs. An important observation to which I will return, however, is that two of these three factors would apply to any regulations directed at mitigating GHG emissions, although the interaction of these factors does make the problem worse in the context of offsets. The first factor is jurisdictional. Offset programs test the limits of international regulatory cooperation in that differing regulatory

agencies in different countries need to at least agree on consistent measurement and reporting metrics, and officials in the "host" countries of projects need to provide or allow 
access to data for verification purposes. Another complication from jurisdictional limits are the many types of indirect impacts that climate policies can have on land-use, energy consumption, and industrial activity in other jurisdictions. These effects include the leakage of emissions to other jurisdictions as well as the types of indirect land-use questions that have come to play a large role in biofuels and forestry policy. All these indirect impacts have the consequence of reducing the actual net reductions of GHG emissions from the level one might measure by focusing only on "local" reductions.

The second institutional issue relates to the strength of regulatory and governance institutions within many of the countries that might seem to be prime candidates for selling offsets. This is perhaps most pronounced in the context of land-use related offsets. ${ }^{3}$ Unfortunately the development of strict environmental measurement, let alone enforcement, practices is likely beyond the resources of the regulatory institutions in many of these countries. This problem is greatly complicated by the fact that the incentives of officials in differing jurisdictions are often not aligned. Developing countries would like to get access to the capital provided by offset programs, and may be less directly concerned about the true mitigation associated with any given project. At least in the context of an offset regime, the enforcement powers in effect reside outside of local jurisdictions. Final accreditation decisions are made by an international governing body in the case of the CDM, and by the U.S. EPA in the case of H.R. 2454.

The third issue, to which I will devote the bulk of our attention in this paper, relates to the fundamental aspect of offset programs. This is the fact that offset programs require a determination of an emissions baseline from which the attributable reductions can be measured. Assuming the institutional issues described above could be overcome, regulators should be able to reliably verify the actual emissions of a facility, or at least a sector. However, baselines (e.g. the emissions in the absence of an offset) by definition cannot be observed since they are the product of a "what-if" exercise. The regulator can hope to accurately measure the emissions of a facility after it registers for an offset, but can only estimate what those emissions would have been if the facility had not sold any offsets. By contrast, under a cap-and-trade program, the baseline is essentially zero, and firms must provide emissions allowances to offset any emissions observed above zero.

\footnotetext{
${ }^{3}$ Murray, et. al. highlight the fact that about half the potential GHG savings from the forestry sector comes from Africa, and that governance and infrastructure improvements are likely necessary before much of that potential can be reliably tapped.
} 
By structuring a program around the concept of paying firms to reduce emissions, offset regimes become vulnerable to two classic regulatory problems; moral hazard and adverse selection. The latter involves paying too much to firms with already low emissions, while the former involves firms actively taking steps to inflate their baselines. I discuss each of these issues in the following subsections.

\subsection{Moral Hazard}

The moral hazard, or perverse incentive, problem stems from the fact that emissions baselines are not only the private information of firms, but can also in some cases be readily influenced by those firms. In the offset context, this can take two forms. Firms (or countries) could actively pursue investments in high-carbon sources, with the intent of earning offset payments to drop those investments. Alternatively, firms or countries could delay investments that would lower emissions from existing sources with the same intention.

One of the most controversial offset initiatives has been the funding of HFC-23 mitigation under the CDM. This is an extremely potent GHG that is a byproduct of industrial coolant manufacturing. Because of its potency, investments to capture HFC-23 emissions qualified for large CDM credits whose value arguably far exceeded the value of the product for which this pollutant was a byproduct. In the face of these obviously perverse incentives, it has been argued that firms expanded or maintained operations solely to qualify for CDM payments to capture their byproduct. ${ }^{4}$ New projects for the capture of HFC-23 may no longer qualify for CDM credits, and activities to capture industrial gases claim an increasingly modest share of newly qualified projects.

\subsection{Adverse Selection}

The primary concern in offset markets is the phenomenon that offset sales will be particularly attractive to firms' whose true baselines are lower than the regulators' estimates. These firms can essentially be paid for "reductions" that would have happened anyway. In the jargon of offset policy, this problem is known as additionality. In H.R. 2454, additional is defined as:

\footnotetext{
${ }^{4}$ See Wara, 2008. Grubb et al. argue that, despite the incentive problems, the program did result in meaningful early reductions in a very potent GHG.
} 
The term additional, when used with respect to reductions or avoidance, or to sequestration of greenhouse gases, means reductions, avoidance, or sequestration that result in a lower level of net greenhouse gas emissions or atmospheric concentration than would occur in the absence of an offset project.

The additionality problem has come to dominate the debates over offset markets, and there is a large amount of enforcement language and effort put into trying to mitigate it. There is also a rich literature on environmental regulation under imperfect information that has also focused on this problem. In this literature, the main culprit is adverse selection. Particularly relevant for this discussion is the work of Montero (1999 and 2000), which examines the consequences of voluntary "opt-in" to a cap-and-trade program. These optin provisions, such in the US SO2 program, bear many similarities to offset mechanisms. In Montero's derivation, allowing opt-in produces a trade-off between the efficiency gains of lower-cost abatement and the "excess emissions" resulting from adverse selection.

However, some of this focus on additionality and the mechanisms deployed to combat it may be misguided as not all additionality problems may stem from adverse selection. A key issue is the extent to which an overestimate of baselines is a firm-specific or aggregate phenomenon. The regulators information about aggregate emissions is also a factor. If the additivity problem stems from the fact that the regulator overestimated the baselines from the entire sector, then the implications of an offset program can be very different. The result is still less "abatement" than expected, but this does not necessarily translate into more emissions than expected.

Consider the case of the Chinese power sector. As Wara (2008) documents, an impressive percentage of new Chinese power plants received CDM credits by virtue of their not being coal plants. Almost certainly, as Wara argues, some of these plants would have utilized non-coal technology in the absence of an offset payment. ${ }^{5}$ However, consider the possibility that future projections of Chinese "business as usual" (BAU) emissions, and consequently emissions caps in the developed world, assumed that new power plants would utilize coal. If this were true, then the BAU projection for the entire Chinese power sector, and therefore of future global emissions was overstated. Viewed in this light, the

\footnotetext{
${ }^{5}$ Haya (2009) provides many examples of energy projects in India that funded under the CDM were not considered additional even by their developers. Lewis (2010), by contrast, emphasizes what she considers a critical role offsets have played in providing financing for Chinese power projects.
} 
CDM provided new information about aggregate emissions, and could in theory allow for reductions from the capped sector to adjust to this new information.

In the sale of offsets, the key information asymmetry lies in the estimates of BAU emissions, in particular for the uncapped sector. It is common in the mechanism design literature to assume that the regulator knows the distribution of information (here expected emissions, or "baselines") but does not know where any specific firm falls in that distribution. This is the asymmetry framework utilized by Montero (2000). In related work (Bushnell, 2010), I represent this as a special case, but it is also important to consider the very real prospect that the regulator may not have perfect information about even the aggregate distribution of baselines. In particular the regulator may be wrong about the expected mean baseline.

\section{Independently Distributed Baselines}

First consider the case where the regulator does know the distribution of baselines, but not the baseline of an individual firm. For any given firm the actual marginal costs of providing offsets might be lower or higher than that of the average firm in the uncapped population. This is because their true baseline emissions from which they must abate may be higher or lower than the regulator's estimate. This "true" cost of offsets, reflects the actual costs of reducing emissions from a baseline level that differs from the regulators estimate. Thus the firms with the lowest actual baselines have the lowest "costs," and in a competitive market these will be firms selling offsets. Conversely, it is the high baseline firms for whom offset sales are most expensive, who stay out of the offset market.

Since the low-baseline firms participate and the high baseline firms do not, the actual reductions from the uncapped sector will be less than the offsets traded and total emissions from the uncapped sector will be greater than the official estimate of reductions. Although the regulator's estimate of total baseline emissions from the uncapped sector are correct, the self selection of low-baseline firms into the offset program leaves only high-baseline firms without abatement. The result, after offsets are transacted, is more emissions than anticipated from the uncapped sector and therefore more emissions overall.

This is essentially the framework examined by Montero (2000). If I assume that the cap is set with optimal desired emissions levels in mind, this excess of pollution becomes a potentially serious problem. There are also savings, as the capped sector spends less to 
abate. Montero demonstrates these trade-offs. ${ }^{6}$

\section{Correlated Baselines Among Uncapped Firms}

An alternative implication emerges as the baseline levels become more highly correlated. Consider the possibility that regulators over-estimate the BAU emissions from the entire uncapped sector. The offset costs of most firms are now lower than the actual costs of abatement since most have to do less abatement than expected. Prices for offsets and allowances are therefore lower and participation in the offset market increases. Although there are more offsets being sold, there is now much less abatement going on, and the share of emissions from the capped sector increases quite a bit relative to the case with no offsets. However, total emissions are actually below the aggregate expected level. This is because of the large negative shock to emissions in the uncapped sector. I define excess emissions as additional emissions above the cap that are created by introducing offsets. In the case of highly correlated baselines, total emissions from the uncapped sector (vertical striped area) can be much lower than expected, even though there is considerable amount of emissions reductions that are not "additional." This is because the low baselines of firms who are selling offsets also imply low baselines even from firms who are not selling offsets.

Note that introducing offsets does increase emissions relative to the no-offset case. In the absence of offsets, aggregate emissions are well below the cap because the low-emissions shock fell outside the cap. ${ }^{7}$ The low realization of baseline emissions make compliance with the cap easier, and allowance prices adjust accordingly. ${ }^{8}$

In this example, the baselines of most uncapped firms are over-estimated. The excess emissions of offset markets are not symmetric to the baseline realization, however. If the

\footnotetext{
${ }^{6}$ If unlimited transfers are allowed, optimal emissions levels can still be obtained by anticipating the adverse selection and reducing the cap in the capped sector by the amount of excess emissions produced by the offsets.

${ }^{7}$ This discussion assumes that the cap is set in terms of emissions, rather than an outcome-based measure such as atmospheric concentration of GHG.

${ }^{8}$ This result is similar but not necessarily identical to what would happen if both sectors were capped. If both were capped, then the lower baselines could lower the aggregate abatement necessary without requiring active abatement from the uncapped sector. This can be more efficient as active abatement (the portion of offset sales require action) could still cost more than the equilibrium permit price. If the abatement quantity required from the capped sector yields a marginal abatement cost, after accounting for the lower baselines, that is less than the cost of abatement from the uncapped sector, it would be more efficient for all active abatement to come from the capped sector - even though less active abatement would be required due to the lower baselines. In this case the "maximal cap" would be more efficient.
} 
baseline emissions are underestimated this simply reduces the amount of offsets sold. In the extreme, if the baselines of all firms are underestimated, then there is no adverse selection problem, in the sense that no firm is being paid to do what it would have done anyway absent a payment. In fact uncapped firms would have to do more abatement than they would receive credit for. While underestimating the BAU emissions of uncapped firms can lead to problems stemming from overall regulations that are, ex post, too lax, these problems are not exacerbated by the existence of an offset market.

In summary, the implications of the adverse selection problem is tied strongly to the assumptions about the distribution of "errors" in the forecast of business as usual emissions. If this error is independently distributed across firms, offsets can produce under-abatement. If the errors are highly correlated, however, the offset market can reveal information about the aggregate baseline and allow the abatement decisions of firms in the capped sector to adjust accordingly.

\subsection{Discussion}

As the previous section demonstrates, the question of additionality can be viewed in two lights; the adverse selection view, in which offsets pay the "wrong" firms to reduce while other firms more than make up the difference, and one in which uncapped firms benefit from a coincidental, surprisingly clean development path. In some circumstances there can be an important distinction between the two types of additionality. If the offset market were dominated by the latter "pleasant surprise" phenomenon, offsets can play a useful role despite the additionality problem.

Of course the degree to which this distinction matters is closely linked to the level of the cap in the capped sector. In the context of Kyoto treaty the reductions required of the signatories are extremely modest. Any prospect of a pleasant surprise among nonsignatories would not come close to constituting the overall reductions called for by the IPCC and other groups. In short, most view the Kyoto treaty as so lax that the world needs every ton of reductions it can produce. This is reflected in the fact that there has been relatively little market for excess reduction credits from Annex 1 Kyoto nations, such as Russia and the U.K., because those excess credits are viewed as coincidental. These credits, known as "hot air," have largely been shunned, although this picture could change 
as Kyoto deadlines approach. ${ }^{9}$ The distinction also has less meaning in the context of voluntary offset markets, where there is no mandatory cap to be adjusted.

Looking forward to a post-Kyoto world, however, the implications change somewhat. If a significant share of developed nations commit to proposed targets of $50 \%$ to $80 \%$ reductions, a pleasant surprise scenario could influence thinking about the needed stringency of those caps. ${ }^{10}$ The potential stringency of future caps is largely dependent upon a political process, and the potential role of offsets plays a part in those negotiations. Those close to this process acknowledge that a tighter cap in the U.S. would be much more likely to gain acceptance if offsets are a part of the picture. If caps in the developed world are set ambitiously enough, this may not be the kind of Faustian bargain that critics of offset markets make it out to be.

On the other hand, if the worst-case IPCC scenarios materialize, even $80 \%$ reductions from developed nations would be insufficient to achieve a stabilization of GHG at levels deemed acceptable by the IPCC. Active abatement would have to be pursued in developing countries. Even under these circumstances offsets can play an important role for some sectors of developing countries.

An examination of the IPCC scenarios (figure 1) for future BAU GHG emissions reveals just how much scope there is for an impact of a coincidentally clean development path. There is a great deal of uncertainty about future emissions, with much of that uncertainty falling in the developing world. While fossil-fuel intensive, high population scenarios imply roughly a tripling of emissions by 2100 , other scenarios imply a peak around 2050 followed by a steady decline.

Another key question is therefore whether additionality is likely to reflect adverse selection or common low baselines. In the case studied by Montero (2000), power plants that opted into the $\mathrm{SO} 2$ program had low baselines because their output was reduced, to be replaced by other plants. The case studies of the CDM appear to be different matters. There is evidence that many projects earned emissions reduction credits while not meeting the broad definition of additionality. The power plant projects identified in India and China may very well have not been additional, but their construction did not imply higher output from some other power facilities.

\footnotetext{
${ }^{9}$ Grubb, et. al, 2010

${ }^{10}$ The Annex I nations under the Kyoto protocol account for roughly half of global GHG emissions today, but under the IPCC A2 scenario this share would decline to under 1/3.
} 


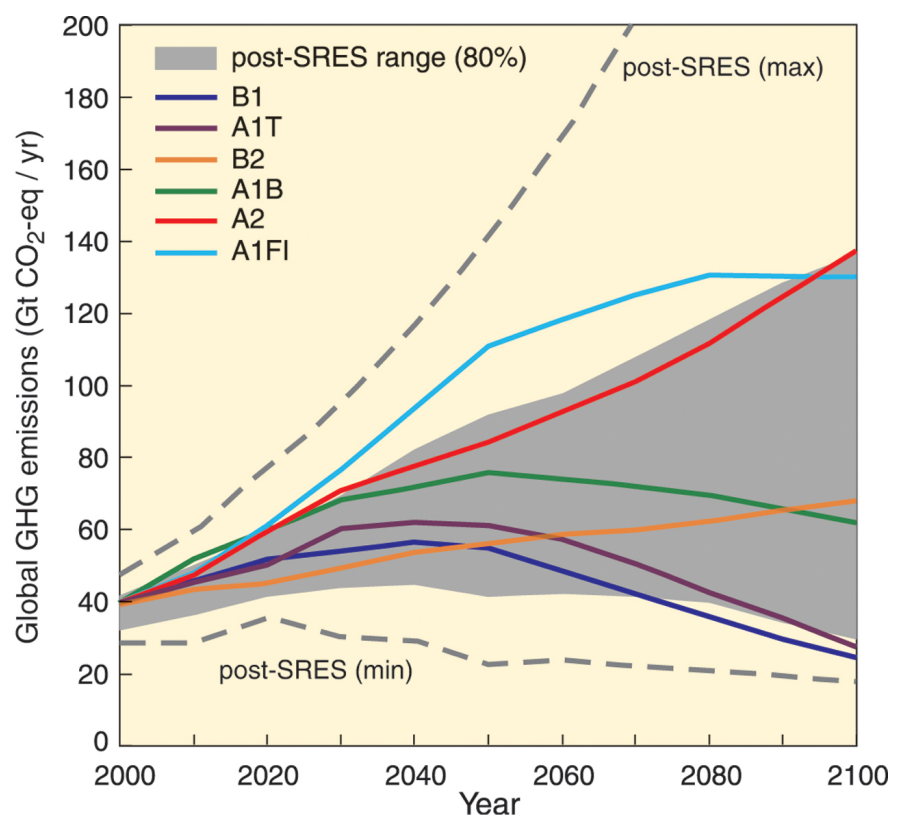

Figure 1: Emissions Trajectories of IPCC Scenarios

\section{Implications for Offset Market Design}

The above discussion attempts to highlight three implications. First, not all forms of additionality should be viewed as equally onerous to the effectiveness and efficiency of emissions caps. Second, the perverse incentives to manipulate baselines are an equally serious concern with no redeeming qualities. Third, offset markets can produce several other types of unintended consequences such as leakage, but those risks apply to almost any measures directed at reducing GHG emissions at less than a global scale. The current regulatory focus on additionality tends to paint all these problems with a broad brush without consideration of the context or their implications.

With these observations in mind, it is useful to consider the various policy tools that have been adopted or considered in order to address the perceived difficulties with offset mechanisms. Importantly, two frequently mentioned solutions, capping the number of offsets and discounting their effectiveness, do not address these problems very well. A cap on the number of offsets allowed into a market can limit the overall severity of the adverse selection problem, but by less than commonly thought. If adverse selection is a serious problem, the projects that are allowed would be the ones with the lowest baseline draws. If the baselines in the uncapped sector are instead highly correlated and much 
lower than expected, then limits on offsets restrict the ability of the mechanism to adjust to the "pleasant surprise" and allow for fewer reductions in the capped sector.

A devaluation of offsets treats all projects as equally non-additional. As I have argued above, if this truly were the case and caps were strict enough in the capped sector, this is precisely when additionality does not reduce efficiency. In fact it produces the exact same outcome as if the uncapped sector were under a mandatory cap and had been allocated allowances equal to its expected baseline. In either case, emissions are reduced and the uncapped sector reaps a windfall. However, both sectors benefit from the added participation of the uncapped sector relative to a case where that participation is limited. If instead baselines are uncorrelated, and additionality is a serious problem, only the most extreme non-additional projects are likely to be financially viable at the reduced returns provided by a generic devaluation.

The solution identified by Montero is very different. A first-best reduction can be achieved if the cap were further tightened in anticipation of the excess emissions yielded from adverse selection in the uncapped sector. This allows full participation by the uncapped sector, but still reaches the same overall emissions aggregated over both sectors. Unfortunately, this approach is both politically difficult and depends upon accurately predicting, on a sectoral level, the severity of the adverse selection problem.

To date the primary bulwark against additionality concerns has been a review process that has been simultaneously criticized as too onerous to allow for substantial investment and also inadequate in weeding out non-additional projects. ${ }^{11}$ While some are concerned this may fatally delay investments, others feel that the incentive problems can only be adequately managed within a small program.

Those concerned with streamlining the review process are attracted to a shift away from project-specific review to a more programmatic approach. This offers several potential benefits. First, a programmatic approach can greatly lower the transactions costs of review and certification relative to the value of the offsets produced. Second, such an approach can help access a broader array of activities including energy efficiency and prevention of deforestation that have been largely absent from markets such as the CDM. Last, a program level review can focus on risks, at an industry level, of the "bad" form of adverse selection while being less concerned with correlated, coincidental reductions. For example,

\footnotetext{
${ }^{11}$ Grubb, et. al. 2010, Victor and Wara, 2008.
} 
investments in building efficiency may very well prove to be economic in the absence of offset programs, and therefore not truly additional. But even if that is the case, increased efficiency in one building is unlikely to imply worse efficiency in others. A programmatic approach can also mitigate the moral hazard problem at the facility level by reducing the importance of the actions at a specific facility. However, there are still concerns about government level incentives.

Last, one tool that has not been applied to offset markets is the application of randomized trials. For example, a population of applications could be chosen to supply offsets while another set is retained as a control group against which to judge the actions of the accepted population. This may be usefully combined with a shift in focus to evaluation at the program or sector level. Such approaches have been usefully applied to address similar adverse selection and moral hazard problems in programs that pay for reductions in energy use. ${ }^{12}$ Atypical increases in emissions from countries or firms that become eligible for offsets relative to those that are not would indicate an inflation of baselines. Measuring the reductions from offset eligible projects relative to others can detect adverse selection relative to a common baseline, but it would also discount gains from commonly shared (e.g. coincidental) reductions. Since, returning to the earlier discussion, there are circumstances in which it is beneficial to allow credits for those coincidental reductions, the treatment of these shared effects would depend upon the stringency of overall caps.

\footnotetext{
${ }^{12}$ Wolak, 2010.
} 


\section{References}

[1] Bushnell, James, B. (2010). "Carbon Offsets and Adverse Selection." Working Paper, Iowa State University.

[2] Grubb, M., Laing, T., Counsell, T. and C. Willan (2010). "Global carbon mechanisms: lessons and implications." Climatic Change. Forthcoming.

[3] Haya, B. (2009). "Measuring Emissions Against an Alternative Future: Fundamental Flaws in the Structure of the Kyoto Protocols Clean Development Mechanism." Energy and Resources Group Working Paper ERG09-001. University of California, Berkeley.

[4] IPCC (2000). IPCC Special Report: Emissions Scenarios.

[5] Lecoq, F., and P. Ambrosi. (2007). "The Clean Development Mechanism: History, Status, and Prospects.". Review of Environmental Economics and Policy. 1(1): 134151.

[6] Lewis, J. (2010). "The evolving role of carbon finance in promoting renewable energy development in China.". Energy Policy. doi:10.1016/j.enpol.2010.01.020.

[7] Montero, J.P. (1999). "Voluntary Compliance with Market-Based Environmental Policy: Evidence from the U. S. Acid Rain Program. " Journal of Political Economy. 107 (5): 998-1033.

[8] Montero, J.P. (2000). "Optimal design of a phase-in emissions trading program.". Journal of Public Economics. 75: 273-291.

[9] Murray, B., Lubowski, R., and B. Shongen (2009). "Including International Forest Carbon Incentives in Climate Policy: Understanding the Economics." Nicholas Institute Report. NI R 09-03. Duke University.

[10] USDA. (2009). "A Preliminary Analysis of the Effects of HR 2454 on U.S. Agriculture." Office of the Chief Economist. Economic Research Service. U.S. Department of Agriculture. July 22.

[11] Victor, D. and M. Wara (2008). "A Realistic Policy for Carbon Offsets." PESD Working Paper 74. Stanford University.

[12] Wara, M. (2008). "Measuring the Clean Development Mechanism's Performance and Potential." UCLA Law Review 55: 1759-1803.

[13] Wolak, F. (2010). "An Experimental Comparison of Critical Peak and Hourly Pricing: The PowerCentsDC Program."Stanford University. 